\title{
UJI LENTUR BALOK BETON BERTULANG MEMADAT SENDIRI HIGH VOLUME FLY ASH 60\%
}

\author{
${ }^{1)}$ Agus Setiya Budi, ${ }^{2}$ Halwan Alfisa Saifullah, ${ }^{3)}$ Lutfi Dwi Rahardian \\ 1),2)Dosen Program Studi Teknik Sipil Fakultas Teknik Universitas Sebelas Maret Surakarta \\ 3) Mahasiswa Program Studi Teknik Sipil Universitas Sebelas Maret Surakarta \\ Fakultas Teknik Jurusan Teknik Sipil Universitas Sebelas Maret Surakarta, \\ Jln Ir. Sutami 36A, Surakarta 57126 \\ Email : lutfirahardian@student.uns.ac.id
}

\begin{abstract}
High Volume Fly Ash - Self Compacting Concrete (HVFA-SCC) is a solution to reduce cement using, and provide concrete that can flow without using compacting tools. This research will examine the bending capacity of HVFA-SCC RC beams by 60\% fly ash content, then will be compared with normal concrete beams. The specimen used in this research is a reinforced concrete beam with a cross sectional area of $10 \mathrm{~cm} \times 18.5$ $\mathrm{cm}$ with a length of $155 \mathrm{~cm}$. Testing of flexural capacity uses a loading frame with 2 points of loading with a distance between loads of $45 \mathrm{~cm}$. From this test, we will get the load-deflection relationship chart, the calculation of bending capacity of concrete beams HVFA-SCC 60\%. Based on the bending capacity test of concrete beams, the value of HVFA-SCC by 60\% fly ash is larger value than the bending capacity of the normal concrete beams.
\end{abstract}

Keywords: Bending capacity, HVFA-SCC, Fly ash.

\begin{abstract}
Abstrak
High Volume Fly Ash - Self Compacting Concrete (HVFA-SCC) merupakan solusi untuk mengurangi penggunaan semen, dan tuntutan beton yang dapat memadat tanpa menggunakan alat pemadatan. Penelitian ini dimaksudkan untuk menganalisis kuat lentur pada balok beton bertulang High Volume Fly Ash - Self Compacting Concrete (HVFA-SCC) 60\% fly ash yang akan dibandingkan dengan balok beton bertulang beton normal yang diuji pada umur beton 28 hari. Benda uji yang digunakan adalah balok beton bertulang dengan luas penampang $10 \mathrm{~cm}$ x 18,5 cm memiliki $155 \mathrm{~cm}$. Pada uji kapasitas lentur digunakan loading frame dengan 2 lokasi pembebanan dengan jarak antar beban sebesar $45 \mathrm{~cm}$. Dari hasil pengujian diperoleh hubungan beban-lendutan yang dinyatakan dalam grafik serta hasil perhitungan kapasitas lentur balok beton HVFA-SCC $60 \%$. Hasil penelitian ini menunjukkan bahwa kapasitas lentur pada balok beton bertulang HVFA-SCC 60\% memperoleh nilai 0,1\% lebih tinggi dibanding dengan beton normal.
\end{abstract}

Kata Kunci : fly ash, HVFA-SCC, kapasitas lentur.

\section{PENDAHULUAN}

Semen sebagai salah satu penyusun beton menjadi salah satu sumber penyebab terjadinya Global Warming (Benhelal dan Zahedi, 2013). Hal tersebut dikarenakan proses pembakaran suhu tinggi pada produksi semen yang mengahasilkan emisi gas $\mathrm{CO}_{2}$. Proses produksi semen ini mencapai 7\% dari keseluruhan gas emisi $\mathrm{CO}_{2}$ yang memicu efek rumah kaca yang menyebabkan Global Warming (Worrell \& Price, 2001). Permasalahan inilah yang mendasari perlunya inovasi beton ramah lingkungan yang berkelanjutan dan bisa digunakan untuk generasi ke depannya, maka diperlukannya sebuah material pengganti semen pada campuran beton.

Penelitian ini menggunakan fly ash sebagai bahan campuran untuk mengurangi komposisi semen dalam powder. (Jatale et al., 2013) menginformasikan bahwa penggunaan fly ash dapat menaikkan workability beton serta mempengaruhi tingkat kekuatan beton yang dipengaruhi oleh faktor air semen $(w / c$ ratio $)$ serta presentase fly ash dalam campuran beton. Fly ash berbentuk butiran halus bulat yang dapat terbang bebas di udara dan dapat mengancam kesehatan apabila terhirup karena mengandung bahan kimia yang tidak seharusnya dihirup oleh manusia seperti silikon dioksida $\left(\mathrm{SiO}_{2}\right)$. Kandungan $\mathrm{SiO}_{2}$ dalam fly ash merupakan bahan pozzolan yang dapat membentuk kalsium hidrat (C-S-H) yang apabila senyawa ini bereaksi dengan kalsium hidroksida $\left(\mathrm{Ca}(\mathrm{OH})_{2}\right)$ pada temperatur biasa akan membentuk senyawa bersifat cementitious (bersifat mengikat), adapun penggunaan fly ash dalam jumlah besar dalam campuran beton atau dikenal sebagai High Volume Fly Ash (HVFA) yang memiliki kandungan fly ash lebih dari 50\% dari total material cementitius.

Beton akan membutuhkan material baja tulangan dalam penerapannya dikarenakan sifat beton yang hanya kuat menahan gaya tekan namun lemah terhadap gaya tarik. Dengan adanya tulangan tersebut, campuran beton harus 
mampu melewati celah antar tulangan dan menghasilkan beton yang dapat memadat tanpa adanya rongga didalamnya agar tidak menurunkan kuat tekan beton itu sendiri. Solusi dari permasalahan tersebut adalah penggunaan beton yang dapat memadat sendiri atau Self Compacting Concrete (SCC) karena beton segarnya lebih cair jika dibandingkan dengan hasil pembuatan beton segar pada beton normal sehingga lebih mudah dalam pengerjaannya.

Besar kapasitas lentur (bending capacity) pada balok beton bertulang HVFA-SCC dengan kandungan fly ash sebesar $60 \%$ akan dikaji dalam penelitian ini. Sampel yang digunakan berupa balok beton bertulang yang nantinya akan dilakukan perbandingan dengan beton normal pada umur uji 28 hari.

\section{METODE}

Penelitian ini dilaksanakan secara eksperimental dengan melakukan sebuah percobaan pada benda uji untuk memperoleh data-data dan diselidiki dalam kondisi terkontrol dengan urutan kegiatan yang sistematis yang selanjutnya dibandingkan dengan hasil perhitungan secara analitis untuk menghasilkan suatu simpulan yang dapat dipertanggungjawabkan.

Pada penelitian ini digunakan benda uji berupa balok beton bertulang dengan profil penampang $10 \times 18,5 \times 155$ cm yang terdiri dari 2 buah balok beton normal dan 2 buah balok beton tipe HVFA-SCC dengan 60\% kandungan pada umur beton 28 hari. Benda uji dimodelkan seperti Gambar 1 berikut:

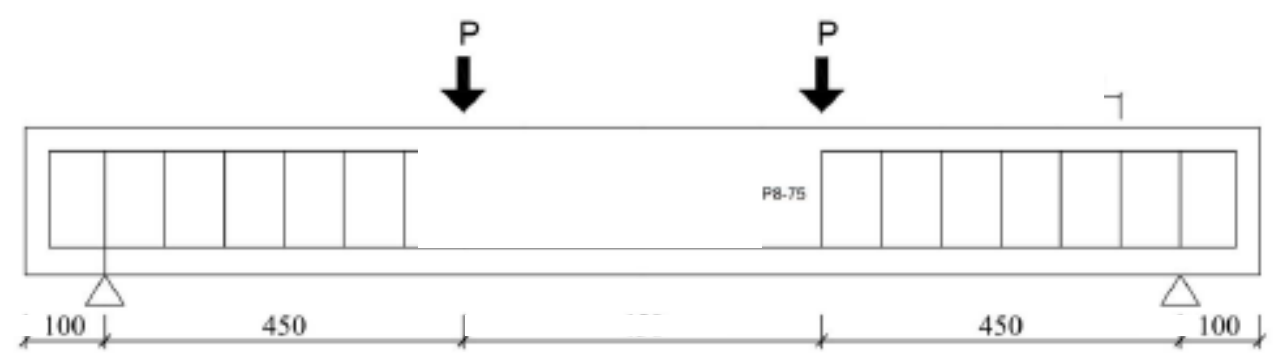

Gambar 1. Model benda uji balok lentur

Setting up alat uji dapat dilihat pada Gambar 2 berikut :

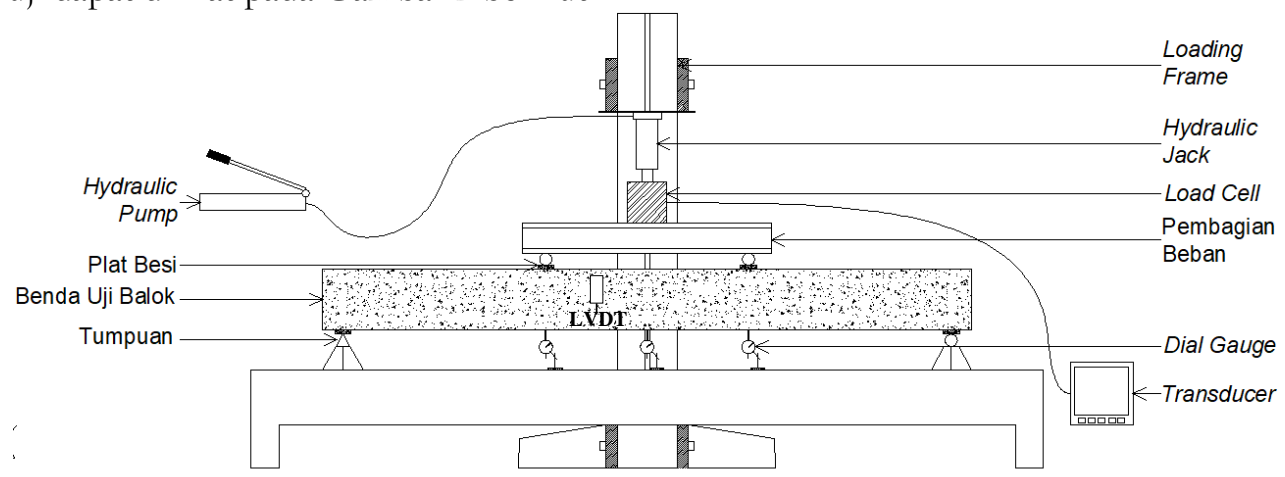

Gambar 2. Setting up alat pengujian balok

\section{Self Compacting Concrete (SCC)}

SCC merupakan campuran beton dengan karakteristik yaitu dapat memadat mandiri tanpa perlu dibantu alat pemadat yaitu vibrator. Selain itu, campuran beton ini memiliki nilai flowability serta workability yang relatif tinggi. Self Compacting Concrete (SCC) ini mempunyai karakteristik khusus lainnya yaitu memiliki volume pori-pori yang kecil pada beton, hal ini dapat mengurangi jumlah udara yang terperangkap dalam campuran beton (Herbudiman, 2012).

\section{High Volume Fly Ash (HVFA)}

High Volume Fly Ash Concrete (HVFA) adalah campuran beton yang menggunakan fly ash bervolume tinggi sebagai bahan tambah. HVFA ini memiliki lebih dari 50\% kandungan semen sebagai material pengganti yaitu fly ash kelas C ataupun kelas F. (Saha \& Rajasekaran, 2017) 
Jurnal Matriks Teknik Sipil DOI: https://doi.org/10.20961/mateksi.v8i3

ISSN: $2354-8630$

E-ISSN: 2723-4223

Vol 8, No 3 (2020): September

\section{High Volume Fly Ash - Self Compacting Concrete (HVFA-SCC)}

Campuran beton ini merupakan inovasi beton SCC terbaru dalam dunia teknologi beton atau dapat dikategorikan sebagai SCC dalam tipe baru yang komposisi materialnya mengandung fly ash dengan jumlah $50 \%$ atau lebih dari total cementitious untuk memperoleh beton yang kuat serta tahan lama.

\section{Kapasitas Lentur Balok}

SNI terkait beton yaitu pada Pasal 10.2.7 memberikan pernyataan terkait izin penggunaan distribusi tegangan tekan persegi ekuivalen untuk dilakukan perhitungan kuat penampang ultimate, kuat lentur dapat dihitung dengan persamaan berikut

$C=0,85 f \dot{c} a k$

$T=A f$

Untuk memenuhi syarat keseimbangan maka $\mathrm{C}=\mathrm{T}$ sehingga didapati

$a=\frac{0,85 f^{\prime} c b}{A f_{y}}$.

Sehingga

$M_{n}=T\left(d-\frac{a}{2}\right)$

\section{HASIL DAN PEMBAHASAN}

\section{Hasil Uji Bahan}

Agregat halus diuji terlebih dahulu pada beberapa lingkup pengujian meliputi absorbtion, apparent specific gravity, bulk specific gravity, bulk spesific SSD (Saturated Surface Dry), kandungan zat organik, dan kandungan lumpur. Hasil uji agregat halus dinyatakan dalam Tabel 1.

Tabel 1. Hasil uji agregat halus

\begin{tabular}{lccc}
\hline \multicolumn{1}{c}{ Jenis Pengujian } & Hasil & Standar & Keterangan \\
\hline Apparent Specific Gravity & $2,59 \mathrm{gram} / \mathrm{cm}^{3}$ & - & - \\
Bulk Specific Gravity & $2,40 \mathrm{gram} / \mathrm{cm}^{3}$ & - & - \\
Absorbtion & $3,09 \%$ & - & - \\
Bulk Specific SSD & $2,48 \mathrm{gram} / \mathrm{cm}^{3}$ & $2,4-2,6 \mathrm{gr} / \mathrm{cm}^{3}$ & Memenuhi syarat \\
Kandungan Zat Organik & Kuning Muda & Kuning Muda & Memenuhi syarat \\
Kandungan Lumpur & $0,6 \%$ & Maks. $5 \%$ & Memenuhi syarat \\
\hline
\end{tabular}

Pengujian agregat kasar yang dilakukan meliputi pengujian absorbtion, apparent specific gravity, bulk specific gravity, bulke. spesific SSD, dan keausan agregat. Hasil uji agregat kasar dinyatakan pada Tabel 2.

Table 2. Hasil uji agregat kasar

\begin{tabular}{lccc}
\hline \multicolumn{1}{c}{ Jenis Pengujian } & Hasil Pengujian & Standar & Kesimpulan \\
\hline Apparent Specific Gravity & $2,75 \mathrm{gram} / \mathrm{cm}^{3}$ & - & - \\
Bulk Specific Gravity & $2,70 \mathrm{gram} / \mathrm{cm}^{3}$ & - & - \\
Bulk. Specific SSD & $2,70 \mathrm{gram} / \mathrm{cm}^{3}$ & $2,5-2,7 \mathrm{gram} / \mathrm{cm}^{3}$ & Memenuhi syarat \\
Absorbtion & $0,73 \%$ & - & - \\
Keausan Agregat & $26,92 \%$ & $<50 \%$ & Memenuhi syarat \\
\hline
\end{tabular}

Kuat tarik baja diuji di Laboratorium Material Teknik Mesin, Fakultas Teknik, Universitas Sebelas Maret Surakarta, dengan memakai mesin UTM (Universal Testing Machine) yang telah memenuhi standar ASTM E8-04. Sampel uji baja yang dipakai adalah baja ulir berdiameter $10 \mathrm{~mm}$ dengan panjang $30 \mathrm{~cm}$ dan telah dibubut sepanjang 6,2 $\mathrm{cm}$ dengan diameter $8 \mathrm{~mm}$. Hasil pengujian ditampilkan dalam Tabel 3 .

Tabel 3. Hasil uji kuat tarik baja Ø16 mm

\begin{tabular}{ccccccc}
\hline $\begin{array}{c}\text { Benda } \\
\text { Uji }\end{array}$ & $\begin{array}{c}\mathbf{D} \\
\mathbf{( m m )}\end{array}$ & $\begin{array}{c}\text { As } \\
\left(\mathbf{m m}^{2}\right)\end{array}$ & $\mathbf{P}_{\text {leleh }}(\mathbf{N})$ & $\mathbf{P}_{\text {maks }}(\mathbf{N})$ & Fy (MPa) & Fu (MPa) \\
\hline A & 10 & 47,78 & 26,70 & 36,13 & 565 & 755 \\
B & 8 & 49,02 & 21,34 & 28,19 & 435 & 575 \\
& \multicolumn{2}{c}{ Rata-rata } & & & 445 & 575 \\
\hline
\end{tabular}




\section{Hasil Uji Beton Segar}

Pengujian beton segar HVFA-SCC 60\% berupa L-Box Test, V-Funnel Test, serta Flow Table Test. Pengujian beton segar beton normal berupa uji Slump. Hasil uji beton segar dinyatakan dalam Tabel 4 hingga Tabel 6.

Tabel 4. Hasil uji flow table test HVFA-SCC 60\%

\begin{tabular}{cccccccc}
\hline & \multicolumn{3}{c}{ Flow Table Test } & \multicolumn{3}{c}{ Syarat menurut } \\
Kode & $\mathbf{d 1}$ & $\begin{array}{c}\text { Diameter } \\
\mathbf{d} 2\end{array}$ & $\mathbf{d}_{\text {rata-rata }}$ & $\begin{array}{c}\text { Waktu } \\
\mathbf{t}_{\mathbf{5 0}}\end{array}$ & $\begin{array}{c}\mathbf{T}_{\mathbf{5 0}} \\
\mathbf{( s )}\end{array}$ & $\begin{array}{c}\mathbf{d}_{\text {rata-rata }} \\
(\mathbf{m m})\end{array}$ & Keterangan \\
& $(\mathbf{m m})$ & $(\mathbf{m m})$ & $(\mathbf{m m})$ & $(\mathbf{d t})$ & $\mathbf{( s )}$ & Memenuhi \\
\hline HVFA $60 \%$ & 600 & 640 & 620 & 3 & $2-5$ & $550-850$ & MARC \\
\hline
\end{tabular}

Table 5. Hasil Uji L-Box HVFA-SCC 60\%

\begin{tabular}{cccccc}
\hline Kode & \multicolumn{5}{c}{ L-Box Type } \\
& $\begin{array}{c}\mathbf{h}_{\mathbf{1}} \\
(\mathbf{m m})\end{array}$ & $\begin{array}{c}\mathbf{h}_{2} \\
(\mathbf{m m})\end{array}$ & $\mathbf{h}_{2} / \mathbf{h}_{1}$ & $\begin{array}{c}\text { Syarat } \\
\left(\mathbf{h}_{2} / \mathbf{h}_{\mathbf{1}}\right)\end{array}$ & Keterangan \\
\hline HVFA $60 \%$ & 90 & 85,5 & 0,95 & $0,8-1,0$ & Memenuhi \\
\hline
\end{tabular}

Tabel 6. Hasil uji v-funnel HVFA-SCC 60\%

\begin{tabular}{cccc}
\hline Kode & T (dt) & Syarat (dt) & Keterangan \\
\hline HVFA $60 \%$ & 6 & $6-12$ & Memenuhi \\
\hline
\end{tabular}

Hasil pengujian beton segar HVFA-SCC 60\% seluruhnya sudah memenuhi syarat beton SCC berdasarkan Specification and Guidelines for Self - Compacting Concrete yang diterbitkan oleh EFNARC.

Pengujian slump pada beton normal diperoleh nilai $10 \mathrm{~cm}$. Menurut SNI 7656 2012, syarat nilai slump beton normal adalah 2,5-10 cm. Maka, hasil uji tersebut memenuhi syarat.

\section{Pengujian Kapasitas Lentur Balok}

Pada uji balok beton bertulang HVFA-SCC 60\% dengan balok beton normal didapatkan keruntuhan balok yang disebabkan adanya gagal lentur, yaitu kapasitas geser balok didesain lebih kuat dibandingkan dengan kapasitas lenturnya. Pembacaan lendutan dilakukan setiap interval pembebanan $0,25 \mathrm{kN}$. Hubungan beban dan lendutan maksimum di titik beban hasil uji kapasitas lentur balok normal serta HFVA-SCC 60\% disajikan pada Gambar 3 dan 4 berikut

\section{HUBUNGAN BEBAN-LENDUTAN MAKSIMUM DI TITIK BEBAN BALOK BERTULANG HVFA-SCC}

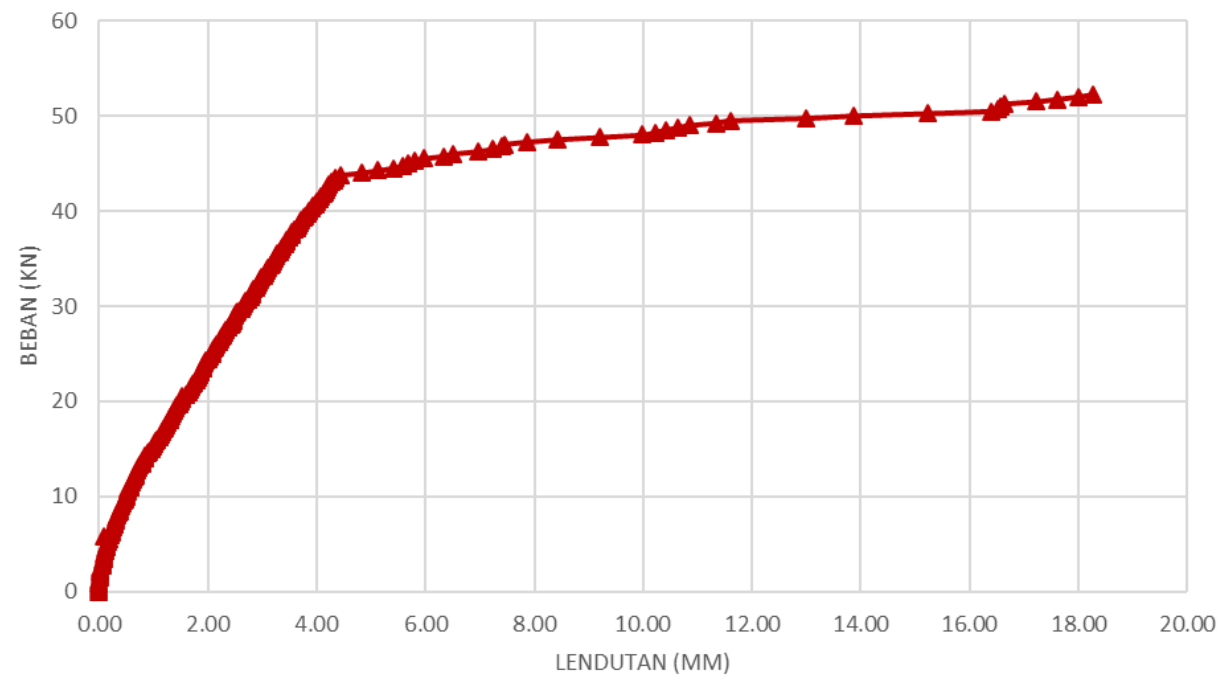

Gambar 3. Hubungan beban-lendutan maksimum di titik beban balok beton bertulang HVFA-SCC 60\% 


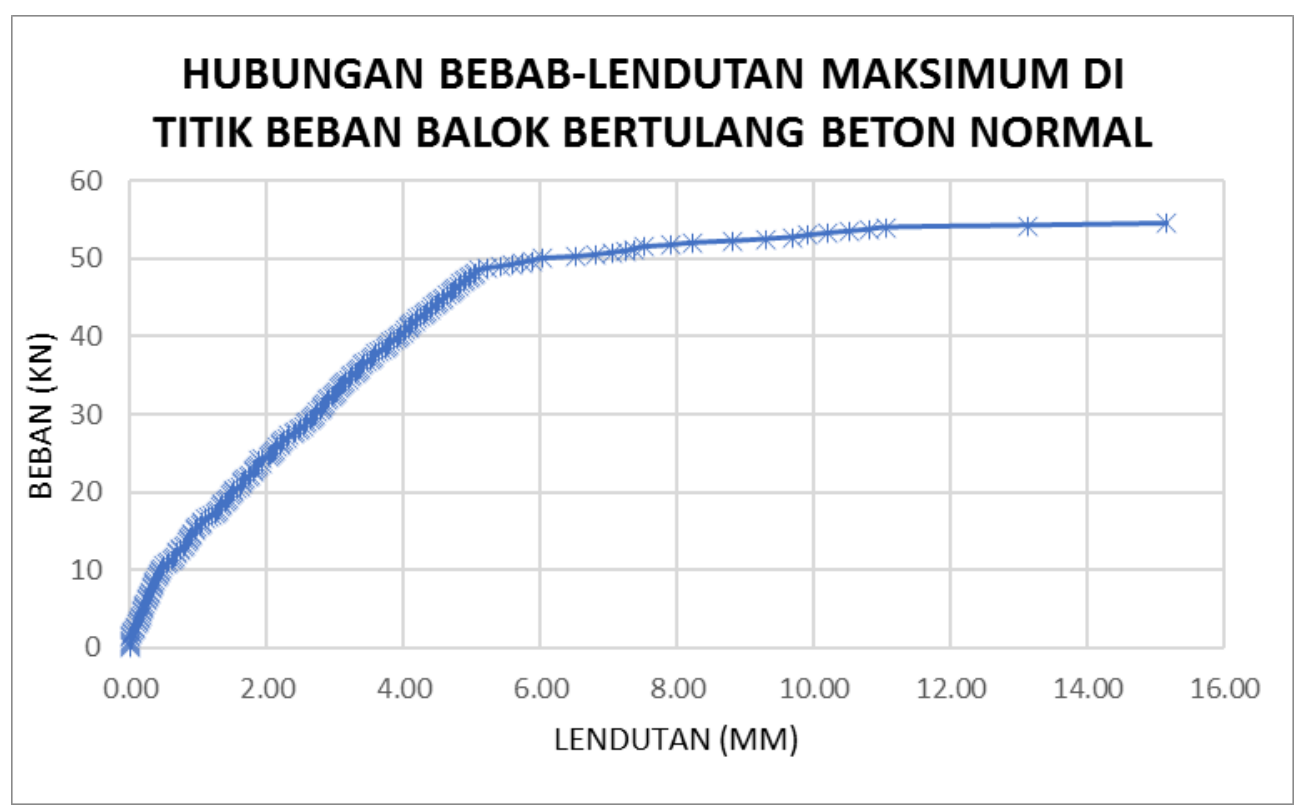

Gambar 4. Hubungan beban-lendutan maksimum di titik beban balok beton bertulang normal

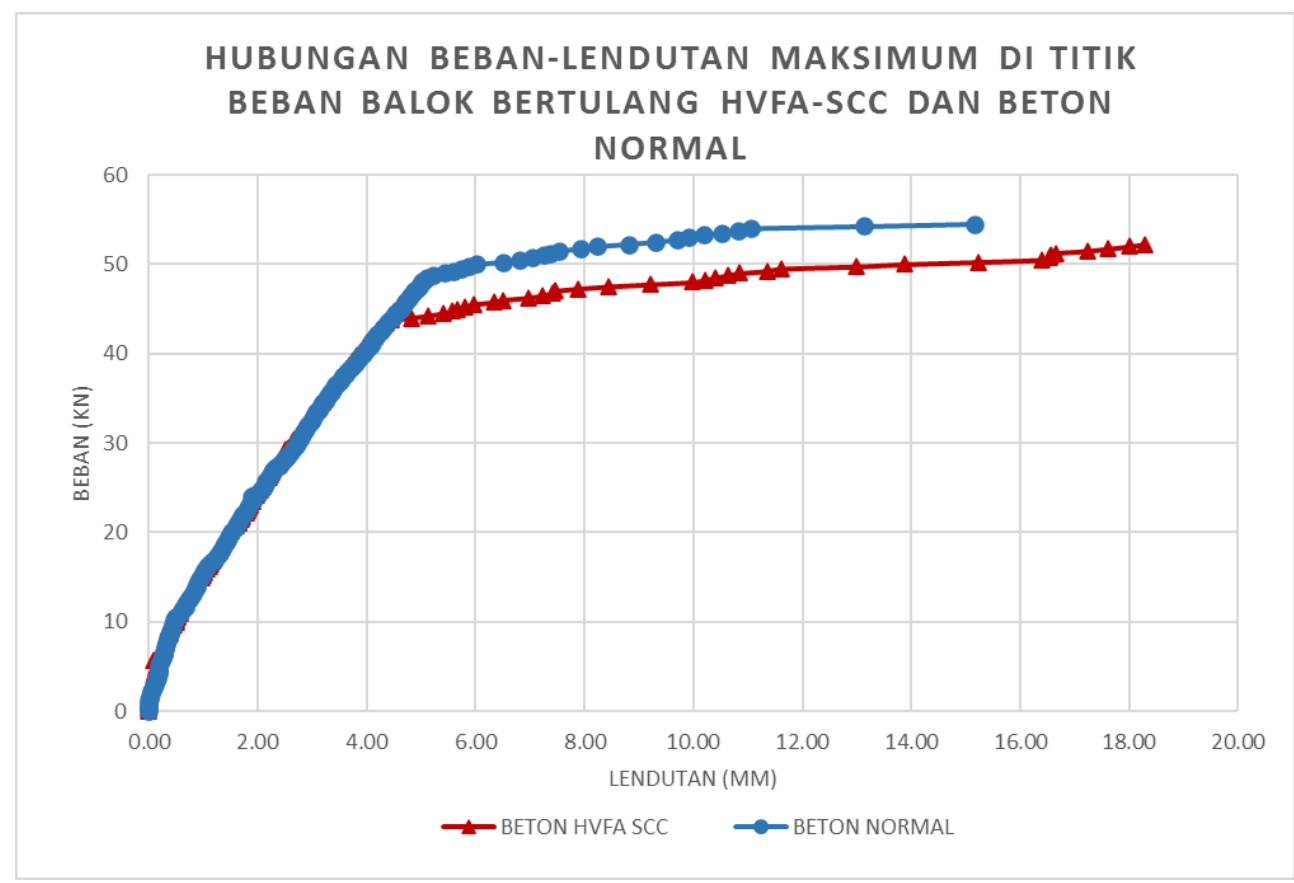

Gambar 5. Hubungan beban-lendutan maksimum di titik beban balok beton bertulang HVFA-SCC dan normal

\section{KESIMPULAN}

1. Lendutan maksimal terjadi di titik beban yang diterima balok beton bertulang HVFA-SCC $60 \%$ adalah 18,28 $\mathrm{mm}$ sementara pada balok beton normal terjadi pada $15,16 \mathrm{~mm}$;

2. Kapasitas lentur balok HVFA-SCC $60 \%$ adalah $12,05 \mathrm{kNm}$ dan balok beton normal 11,04 kNm.

\section{UCAPAN TERIMA KASIH}

Ucapan terima kasih penulis sampaikan kepada Bapak Agus Setiya Budi, S.T., M.T. dan Dr. Eng. Halwan A. S. S.T., M.T. selaku pembimbing yang dengan penuh kesabaran telah memberi koreksi dan arahan sehingga menyempurnakan penyusunan, terima kasih juga untuk Arfah Pujianto, M. Mar.Eng dan Yayuk Muji Rahayu atas segala dukungan serta doanya, terima kasih juga untuk Dirsta Alifia B M yang selalu memberi ide dan saran. Rasa terima kasih penulis sampaikan khusus untuk tim OTW Rektorat yang sudah berjuang bersama. 


\section{DAFTAR PUSTAKA}

Benhelal, Emad, and Gholamreza Zahedi, 2013, "Global Strategies and Potentials to Curb CO2 Emissions in Cement", Journal of Cleaner Production. Vol. 51, pp. 142-161.

Herbudiman B., and Dewi L., D., 2012, "Beton Ringan Self-Compacting dengan Agregat dan Powder Limbah Pecahan Genting Merah”, Konfrensi Nasional Teknik Sipil, Universitas Trisakti, Jakarta.

Jatale, A., Tiwari, K., \& Khandelwal, S. 2013. "Effects on compressive strength when cement is partially replaced by fly ash". IOSR Journal of Mechanical and Civil Engineering, Vol. 5 No. 4, pp. 34-43.

Saha, Suman, and C. Rajasekaran, 2017, "Enhancement of the properties of fly ash based geopolymer paste by incorporating ground granulated blast furnace slag ". Construction and Building Materials, Vol. 146, pp. 615620.

Worrell, Ernst, and Lynn Price, 2001, "Carbon DioxidetEmissions from the Global Cement Industry", Annual Review of Energy and the Environment, Vol. 26, pp. 303-329. 